\title{
Costa Rica sin Fronteras
}

Pensar en Movimiento:

Revista de Ciencias del Ejercicio y la Salud ISSN 1659-4436

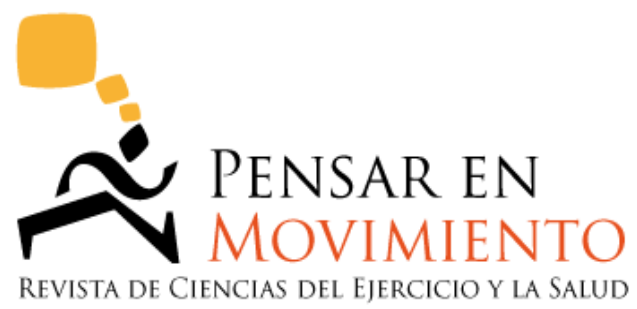

Vol. 17, No.2, pp. 1- 4

Abre $1^{\circ}$ de julio, cierra 31 de diciembre, 2019

\section{COSTA RICA SIN FRONTERAS \# 20}

En esta sección se publican los resúmenes en español de artículos que han sido publicados por investigadoras/es de universidades costarricenses en otras revistas en el mundo, con su debida referencia al trabajo original, y con una breve explicación de dónde se realizó la investigación. Los artículos originales han sido publicados en otros idiomas; las revistas tienen consejo editorial y manejan un proceso de revisión por pares.

Los resúmenes corresponden a estudios relacionados con las ciencias del ejercicio y la salud, que se conforman a los criterios generales de la revista, esto es, se trata de "... estudios experimentales o que hagan recomendaciones concretas para solucionar problemas 0 preguntas relevantes (...) trabajos originales o de meta-análisis." Solicitamos a quienes hayan publicado este tipo de trabajos en otros idiomas que no los hagan saber, para incluir sus resúmenes en futuras entregas de esta sección.

\section{Luis Fernando Aragón V., Ph.D., FACSM Director, PENSAR EN MOVIMIENTO}




\section{EFECTO DE DIFERENTES PROGRAMAS DE MOVIMIENTO EN LA COMPETENCIA MOTRIZ: UNA REVISIÓN SISTEMÁTICA CON METAANÁLISIS}

Jiménez-Díaz, J., Chaves-Castro, K., \& Salazar, W. (2019). Effects of Different Movement Programs on Motor Competence: A Systematic Review With Meta-Analysis. Journal of Physical Activity and Health, 16(8), 657-666. https://doi.org/10.1123/jpah.2018$\underline{0179}$

Evaluar la efectividad de diferentes tipos de programas de movimiento en la competencia motriz (CM) de participantes de todas las edades utilizando la técnica metaanalítica. Se realizó la búsqueda de los estudios por medio de 13 bases de datos y se incluyeron los que cumplieran con los criterios de inclusión. La selección y extracción de los datos la realizaron dos autores. Se calculó la diferencia estandarizada entre medias utilizando el modelo de efectos aleatorios para obtener el tamaño de efecto (TE) global. Se examinó el riesgo de sesgo, la heterogeneidad y la inconsistencia. Treinta y seis estudios cumplieron los criterios inclusión. Se calcularon un total de 374 TE y separados en 4 grupos (intervención motriz, juego libre, clases de Educación Física y grupo control). Se encontró una mejora significativa en CM (TE $=1.50 ; I C 95 \%=1.18$ a $1.82 ; n=36)$, de igual manera en juego libre ( $T E=0.33 ; I C 95 \%=0.09$ a $0.57 ; n=5$ ), clases de Educación Física ( $T E=$ $0.52 ; I C 95 \%=0.08$ a $0.97 ; n=15)$, mientras que una significancia más pequeña se observó en los grupos control ( $T E=0.16 ; I C 95 \%=0.01$ a $0.31 ; n=6$ ). Los 4 grupos analizados mejoran el $\mathrm{CM}$ en niños, adolescentes y adultos. Sin embargo, las intervenciones motrices fueron más efectivas que los otros grupos en mejorar el CM.

Palabas clave: actividad física, educación física, salud, intervención motriz, comportamiento motor

La revista Journal of Physical Activity and Health, es una revista de Human Kinetics, presenta un Factor de Impacto de 2.079 y un Índice H de 60 para el año 2019., tiene una calificación de 1.04 en SCImago Journal Rank (SJR) y de 2.12 en CiteScore en el año 2018. 


\section{LAS TIRAS REACTIVAS DE ORINA SON INEXACTAS PARA LA EVALUACIÓN DE LA HIPOHIDRATACIÓN: UN BREVE INFORME}

Adams, J. D., Capitan-Jiménez, C., Huggins, R. A., Casa, D. J., Mauromoustakos, A., \& Kavouras, S. A. (2019). Urine Reagent Strips Are Inaccurate for Assessing Hypohydration: A Brief Report. Clinical Journal of Sport Medicine, 29(6). http://doi.org/doi:10.1097/JSM.0000000000000555

Objetivo: evaluar la capacidad de diagnóstico de las tiras reactivas de orina para identificar la hipohidratación en función de la gravedad específica de la orina (GEO). Diseño: Este estudio examinó la concordancia del GEO entre las tiras reactivas y refractometría con Bland-Altman, mientras que la capacidad de diagnóstico de las tiras reactivas para evaluar la hipohidratación se realizó mediante el análisis de las características operativas del receptor. Lugar: práctica de pretemporada de fútbol de la escuela secundaria de Arkansas. Participantes: Se analizaron cuatrocientas catorce muestras de orina fresca. Principales medidas de resultado: La gravedad específica de la orina se evaluó mediante tiras reactivas y refractometría. Se utilizaron valores de corte de 1.020 y 1.025 para identificar la hipohidratación. Resultados: el análisis de BlandAltman mostró acuerdo entre los 2 métodos. La capacidad diagnóstica general de la tira de orina para identificar la hipohidratación fue regular (área bajo la curva $72 \%-78 \%$ ). Sin embargo, la sensibilidad para identificar correctamente la hipohidratación fue pobre $(63 \%$ $71 \%)$, y la especificidad de identificar correctamente la euhidratación fue de pobre a regular (68\% -83\%). Conclusión: el método de la tira de orina no es válido para evaluar la hipohidratación.

Palabras claves: gravedad específica de la orina, refractometría, hidratación aguda

La revista Clinical Journal of Sport Medicine tiene un índice de impacto (factor de impacto) de 2.702, según su propia página y una calificación de 0.99 (índice $H=94$ ) según Scimago Journal Rank (SJR) año 2018. Este estudio se realizó durante una pasantía doctoral en el Human Performance Laboratory de Arkansas University, bajo la supervisión del Dr. Stavros A. Kavouras, entre agosto y diciembre del 2014. Colaboradora: Catalina Capitán Jiménez. 


\section{EL ANÁLISIS DE LAS TIRAS REACTIVAS DE ORINA BASADO EN TELÉFONOS INTELIGENTES ES INEXACTO PARA EVALUAR LA DESHIDRATACIÓN}

Adams, J. D., Capitan-Jimenez, C., Burchfield, J. M., Jansen, L. T., \& Kavouras, S. A. (2019). Smartphone-Based Analysis of Urine Reagent Strips Is Inaccurate for Assessing Underhydration.

Telemedicine and E-Health. https://doi.org/10.1089/tmj.2019.0101

Antecedentes: la hidratación adecuada es vital tanto para el ejercicio como para la salud en general. Aunque existen varios métodos para la evaluación de la hidratación, muchos no son válidos para su uso o nunca se han probado. Introducción: El propósito de este estudio fue determinar si la aplicación $u C h e k^{(\mathcal{C}}$ para teléfonos inteligentes se puede usar para diagnosticar la deshidratación comparada con la gravedad específica de orina (GEO) evaluada por refractometría. Métodos: Ciento cuarenta y siete $(n=147)$ muestras de orina humana frescas, de adultos jóvenes y mediana edad se analizaron para GEO con un refractómetro y la aplicación $u_{C h e k^{(}}$la cual lee una tira reactiva de orina Siemens Multistix 10G. Resultados: el análisis de Bland-Altman mostró acuerdo entre los dos métodos de evaluación. La capacidad diagnóstica general de $\left.u C h e k^{(}\right)$para identificar la deshidratación fue regular (área bajo la curva del 79\%). Sin embargo, la sensibilidad para identificar correctamente la deshidratación fue pobre $(60 \%)$, así como la especificidad para identificar correctamente la euhidratación (53\%). Conclusión: la aplicación $u$ Chek ${ }^{\complement}$ no detecta con precisión la deshidratación.

Palabras claves: gravedad específica de la orina, refractometría, hidratación aguda

La revista Telemedicine and E-Health tiene un índice de impacto (factor de impacto) de 1.996, según Journal Citation Reports para 2018 y una calificación de 0.86 (índice $\mathrm{H}=58$ ) según Scimago Journal Rank (SJR) año 2018. Este estudio se realizó durante una pasantía doctoral en el Human Performance Laboratory de Arkansas University, bajo la supervisión del Dr. Stavros A. Kavouras, entre agosto y diciembre del 2014. Colaboradora: Catalina Capitán Jiménez. 